\title{
The Effect of Bad Heat Treatment Technology on Failure Mode of Armor Steel Sheet under EN1522 Ballistic Test
}

\author{
M.K. El-Fawakhry ${ }^{1, *}$, A.M. Fathy ${ }^{2}$ \\ ${ }^{1}$ Steel Technology Department, Central Metallurgical Research and Development Institute, Egypt \\ ${ }^{2}$ Quality control Department, Ezz Flat Steel, El Shokhna, Egypt
}

Corresponding author: E-mail: Mohamed.elfawkhry@gmail.com, Tel: (+20) 01152529685

Received 4 March 2021

Revised 31 May 2021

Accepted for publication 10 June 2021

Published online 30 June 2021

\begin{abstract}
Armor steel is a special grade of steel that is commonly designed for providing protection of the army resources from different piercing ammunitions. This steel must be assessed through its mechanical properties, and its ballistic resistant to confirm their ability to withstand the resistance of armor-piercing ammunition, before being subjected to use. Case study of armor steel sheet $6 \mathrm{~mm}$ thickness that has been subjected for normal ballistic test EN1522, one projectile passed through the sheet, while the other two projectiles have fired at the surface of the sheet. Then, this research was designed to investigate the root cause of failure of this armor steel sheet $6 \mathrm{~mm}$ under ordinary ballistic test. Constituent structures of steel have been monitored and estimated by using Optical, Scanning electron microscope, Micro hardness tester, and X-ray diffractometer. In addition, hardness map at the surface of the investigated sheet has been detected. Finally, thermal transformation of this steel has been determined by using Dilatometer. The results refer that the root cause of failure should be attributed to the inhomogeneity in the microstructure among the sheet area, which certainly refers to the poor homogeneity at the heat treatment cycle used at the production site.
\end{abstract}

Keywords: Armor steel; Ballistic test; Depth of penetration; Tempered martensite; Retained austenite

\section{Introduction}

Armor steel is such grade of steel, which is distinguished by its high strength and energy absorbing properties, offering many armor applications for personnel, military and non-military vehicles. Failure modes of this grade of steel were well analyzed in different occasions [1]. Four root causes were well mentioned in different occasions:

First one is the microstructure inhomogeneity: the ability of steel to absorb high strain energy with less plastic flow, and free of failure modes is mainly attributed to its distinct microstructure [2]. Hard tempered martensite with fine morphology and adequate fraction of much stable retained austenite absorb excess of strain energy through induced plasticity transformation into bcc- martensite. It was reported that retained austenite should be in the range of $3-5 \%$, and must be very stable [3, 4]. In addition, fewer fractions of non-metallic inclusions as $\mathrm{MnS}$ inclusions must have been reduced to its lower fraction. Regarding to its ability in promoting a crack initiation through the plastic deformation with high strain rate, providing lamination as a failure mode [5].

The second cause is the adiabatic Shear band (ASB) phenomenon: this phenomenon is specific event that should be established at the ballistic test of armor steel. During the initial interaction of a projectile and armor plate, the material directly under the projectile is rapidly accelerated, creating a velocity discontinuity, which gives rise to plastic localization under adiabatic conditions. For susceptible materials and where there are stable velocity discontinuities, the lack of thermal diffusion results in high temperatures and thus thermal softening that overcomes local strain and strain-rate hardening effects. The result is a significant reduction in shear strength and localized deformation. This failure mode ASBs can propagate through the plate thickness, resulting in an adiabatic shear failure mechanism that occurs at low energy levels compared to other classical failure models, e.g., ductile hole [6]. The majority of ASBs formed in the shear direction, which is parallel to the projectile velocity direction. The cracks preferentially propagated along ASBs, leading to adiabatic shear failure and plug ejections. Then, ASB 
can be visually detected at the failed site, through examining the front and rear side of the tested sheet.

The third root cause of failure is segregation: Whereby, steel is not chemically homogeneous. The solidification process causes macroscopic as well as microscopic partitioning of chemical elements as the liquid metal cools. Macroscopically, segregation occurs at the centerline of continuously cast products and at the centerline, top and bottom of ingots. Microscopically, segregation occurs between dendrites throughout the solidified section. Subsequent mechanical hot working (e.g., rolling) creates longitudinal bands of varying elemental chemistry. The segregation of substitutional alloying elements (e.g., manganese, chromium, molybdenum) during (dendritic) solidification is causing banding. Cooling rate, austenitic grain size and austenitizing temperature also influence the severity of microstructural banding. Hardness and microstructure will be heavily influenced by segregation and banding. Although, the segregation is rarely occurring in low alloy steel, as Armor steel, but it was further mentioned that there is a strong relationship between microsegregation and temper embrittlement. It was proved that the segregation is established by some alloying elements as $\mathrm{P}, \mathrm{Ni}$, and $\mathrm{Mo}$ on the parent austenite grain boundaries causing temper embrittlement. In fact, further investigations on this issue proved that $\mathrm{Ni}$, and $\mathrm{P}$ the most significant alloying elements that can segregate at the parent austenite grain boundaries. While, Mo appears to retard the segregation, due to $\mathrm{Mo}_{2} \mathrm{C}$ precipitates that form at elevated temperatures, causing desegregation of Mo from the parent austenite grain boundary (PAGB) [7].

The last cause of failure is the hydrogen embrittlement (HE): Hydrogen can poison the steel through its different manufacturing processes. Hydrogen embrittlement refers to the degradation in the mechanical properties of steel due to hydrogen. It causes subcritical crack growth at stress lower than yield strength and then it leads to loss of ductility of the steel. It was proved that the advanced high strength steel or tempered martensite domain steel is considered as the most significant grade of steel that is $\mathrm{HE}$ susceptible, but it was well proved that $\mathrm{NbC}$, and $\mathrm{TiC}$ precipitates are trapping the hydrogen atom preventing its mobility into the matrix. In addition, it was well proved that retained austenite has a capability on retarding H.E., owing to its low absorbing capacity of hydrogen. Although, tempered martensite domain steel is the most susceptible domain structure for $\mathrm{HE}$, but it was well proved that HE has no effect on high strain rate deformation [8]. Surely, the ballistic test is established at high strain rate, $>800 \mathrm{~S}-1$. In addition, $\mathrm{HE}$ is less occurred in hot rolled steel, like high hardness amour steel (HHA). Then, it is believed that
HE cannot be established at the case of armor steel failure at the ballistic test.

\section{Material and Methods}

Sheet sample with dimensions $300 * 300 * 6 \mathrm{~mm}$ armor sheet after ballistic test according to EN1522 has been photographed from different angle to report on the visual observations at the failure and non-failure sites on the sheet. DOP (depth of penetration) has been calculated at the shoot sites. Hardness map was conducted by using hardness Brinel tester at the sheet to find out the actual distribution of hardness among the sheet. Samples have been cut by using (Electric discharge machine) EDM to cut off the samples required for emission spectrometer, dilatation, optical observation at optical and Scanning Electron Microscopes. Dilatometer was used for determining the thermal profile of the steel alloy at wide range of temperature room temperature to $1100^{\circ} \mathrm{C}$ with constant heating rate and cooling rate $10^{\circ} \mathrm{C} / \mathrm{min}$. Microhardness test has been conducted by using micro indenter at load $50 \mathrm{gm}$ to identify the hardness distribution among the microstructure either at the failed or non-failed sites. Finally, XRD by using Cobalt source diffractometer has been conducted on the samples collected from the sites tested to monitor the crystal structure at these sites, calculating the quantity of phases by using Rietveld refinement. Dislocation density, martensite grain size has been calculated by measuring the microstrain, and applying into different empirical equations.

\section{Results \& Discussion}

\subsection{Chemical analysis}

The chemical analysis of armor steel sheet with 6 $\mathrm{mm}$ thickness shows similarity of the chemical composition of this steel with HHA (high hardness armor) steel. There is no further deviation in the main alloying elements as being observed in Table $1 . \mathrm{Nb}$ and $\mathrm{Ti}$ are observed as micro-additions to the investigated steel, which should have distinct effect on promoting the mechanical properties, owing to their carbides' precipitation affinity. These precipitates have the strong effect on increasing the yield and ultimate strength through precipitation strengthening mechanism.

\subsection{Critical transformation temperatures}

Figure 1 shows that the critical transformation temperature that has been monitored by diltation curve is closed to that was observed by using thermocalc software, TCER database. At $800 \mathrm{oC}$, full austenite structure can be observed, while it started at $680 \mathrm{oC}$. Martensite start temperature was determined at $280 \mathrm{oC}$. In addition, martensite start has been calculated, based on chemical compositions of the steel, using empirical equation (1): 
Table 1 Chemical composition of $6 \mathrm{~mm}$ armor steel sheet failed, and the conventional Armox 500 steel.

\begin{tabular}{|c|c|c|c|c|c|c|c|c|c|c|c|c|}
\hline \multirow{2}{*}{ Item } & \multicolumn{10}{|c|}{ Chemical Composition, wt \% } \\
\cline { 2 - 13 } & $\mathrm{C}$ & $\mathrm{Mn}$ & $\mathrm{Si}$ & $\mathrm{Al}$ & $\mathrm{Ni}$ & $\mathrm{Cr}$ & $\mathrm{Mo}$ & $\mathrm{Ti}$ & $\mathrm{Nb}$ & $\begin{array}{c}\mathrm{B} \\
\mathrm{ppm}\end{array}$ & $\begin{array}{c}\mathrm{N} \\
\mathrm{ppm}\end{array}$ & $\begin{array}{c}\mathrm{H} \\
\mathrm{ppm}\end{array}$ \\
\hline Armox 500 & $\leq 0.32$ & $\leq 1.20$ & $\leq 0.40$ & - & $\leq 1.80$ & $\leq 1.00$ & $\leq 0.7$ & - & - & $\leq 50$ & $\leq 90$ & $\leq 2$ \\
\hline $\begin{array}{c}\text { Armor sheet, } \\
\mathbf{6} \mathbf{~ m m}\end{array}$ & 0.27 & 0.86 & 0.42 & 0.056 & 0.90 & 0.65 & 0.45 & 0.011 & 0.034 & 21 & 82 & 2 \\
\hline
\end{tabular}

Ms $\left({ }^{\circ} \mathrm{C}\right)=500-333 \mathrm{C}-34 \mathrm{Mn}-35 \mathrm{~V}-20 \mathrm{Cr}-17 \mathrm{Ni}-11 \mathrm{Mo}-$ $10 \mathrm{Cu}-5 \mathrm{~W}+15 \mathrm{Co}+30 \mathrm{Al}+0 \mathrm{Si}$

Then, martensite start was calculated around $340 \mathrm{oC}$. By using common regime with the lowest quenching temperature around room temperature, it is predicted that the retained austenite will be $3.5 \%$ according to the equation (2):

$$
\text { R.A. } \%=\exp (-1.1 * 10-2(\mathrm{Ms}-\mathrm{Tq})
$$

\subsection{Visual observations}

The profile of armor sheet containing failed and nonfailed sites Armor steel sheet $6 \mathrm{~mm}$ thickness has been photographed and visual monitored at different sites to interpret the mechanism of failure. At the meantime, the depth of penetration has been calculated at non-failed sites, as given in Fig.2, and 3. It is clear that the three sites have different positions regarding to $2 \mathrm{D}$ coordination axis. In addition, some deviation is observed at the triangle of shooting rather than mentioned in EN1522, but it is still at range. Based on this observation, it is a must to make hardness map for the armor sheet, to evaluate the difference of hardness at different coordination sites, as will be discussed later.

\subsubsection{Determining the strain capacity at the sites of ballistic test}

The bullet dimensions at ballistic test according to EN1522 is $7.62 \mathrm{~mm}$ diameter and height $50 \mathrm{~mm}$. The sign of bullet at either Failed or non-failed location has been detected. It was found that there is much plastic flow happened at the failed site, in comparing with nonfailed site. Certainly, this indicates that the failed location has a lower plastic strength than non-failed location. Reduction in plastic strength, or yield strength of domain martensite structure should be attributed to precipitation of secondary phase or micro-segregation of alloying elements at this location. Based on strain calculations, it was found that non-failed location has been strained by $(11.18-7.62) * 3.14=11.17 \mathrm{~mm}$ with no failure. However, the failed site was strained by $15.38 \mathrm{~mm}$ followed by crack at the rear side as given in Fig.3, and 4. These observations indicate that the hole observed at the failed location is ductile hole failure mode rather than other failure modes like ASB failure mode, or fragmentation mode, as explained in Fig.5. Based on the deformation at the horizontal axis, it can be observed that the bending strength of non-failed area is higher than bending strength on failed area. Regular bending angle is clearly observed at non-failed area, while irregular bending angle is observed at failed area. The reduction of thickness at non-failed site reaches $16 \%$, while it is $3.3 \%$ at failed locations, as given in Fig.6. From these observations and calculations, it should be clear that there is less elastic strength structure has been formed at the failed area, which can reduce the plastic strength of this area to its ultimatum.

\subsubsection{Ballistic performance at non-failed locations}

Non-failed sites at the armor steel sheet have another indication on the high strain rate deformation occurred by the projectile at the ballistic test. As shown in Fig.7, Depth of penetration can be calculated for non-failed sites. In fact, the change of depth of penetration is another sign on the discrepancy in constituent phases among the investigated sheet. It was found that the depth of penetration is $1.2,1.95$ at non-failed sites, which represents huge discrepancy of the ballistic performance at different sites of armor steel sheet $6 \mathrm{~mm}$. Certainly, the phases identification methods, using SEM, and XRD will explain the disparity in ballistic performance among the investigated armor sheet.

\subsection{Hardness map}

Hardness map among the armor steel sheet is must to identify the difference of hardness through the area of the armor steel sheet. The hardness test was carried out at regular coordinate throughout the investigated sheet, and the hardness value in coordination with location $(X$, $\mathrm{Y}$ ) has been plotted in contour to find out the relation between the coordinates among the armor sheet and the hardness value, as given in Fig.8, and 9. It is clear that hardness increment established at the lower rolling direction value, while the hardness has been deteriorated at the end of rolling direction. In fact, the discrepancy of hardness should refer to either inhomogeneity in the constituting structure, or segregation of alloying elements. However, the increment of hardness at one side of sheet at the 


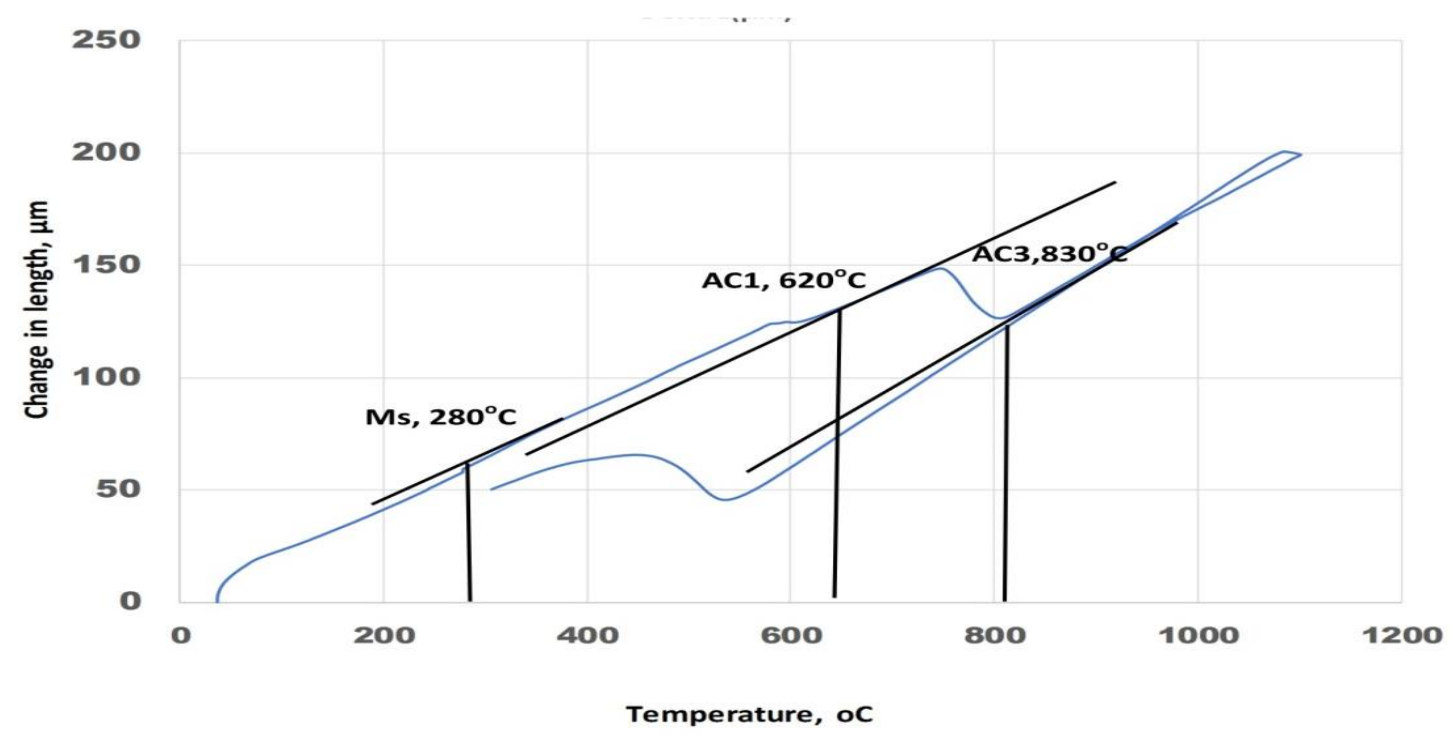

Fig. 1 Dilatation of $6 \mathrm{~mm}$ steel

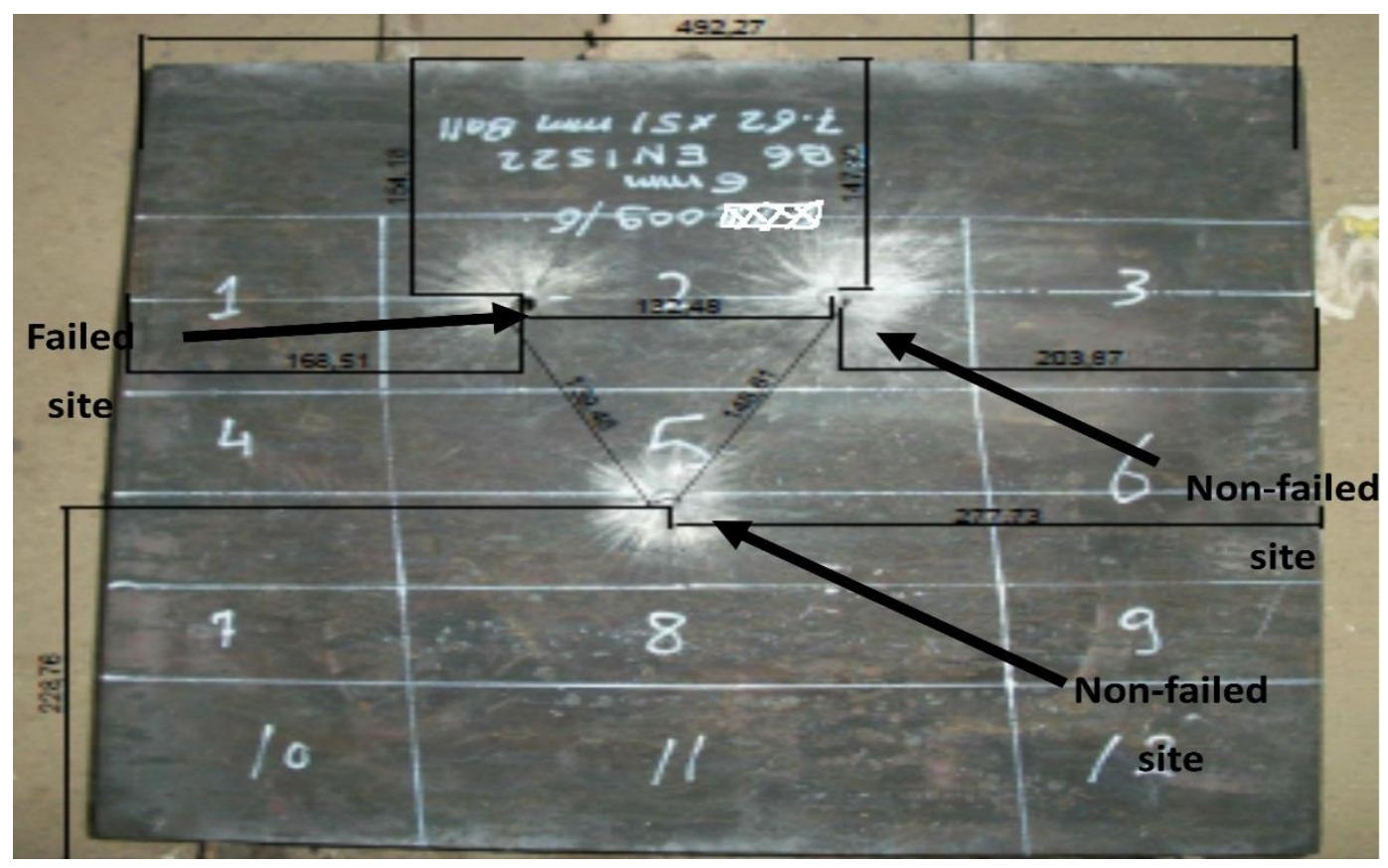

Fig. $26 \mathrm{~mm}$ armor steel sheet after ballistic test. 


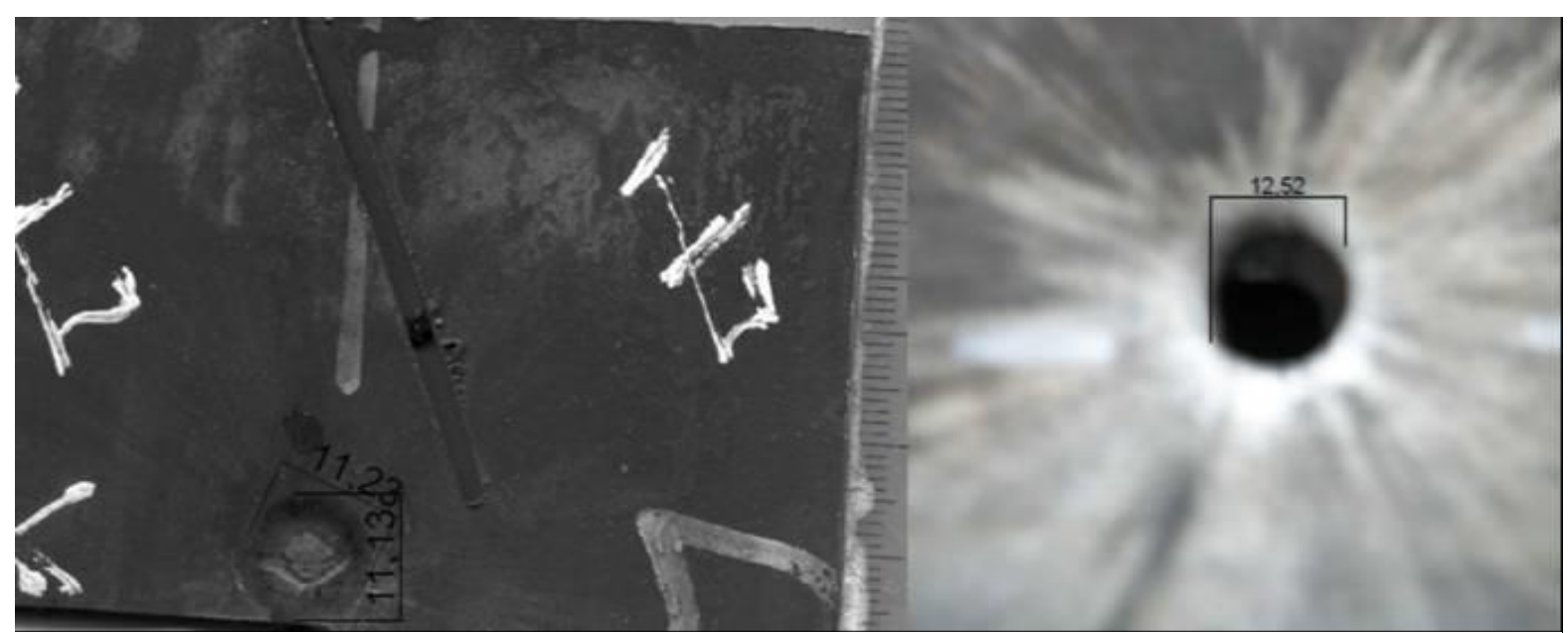

Fig. 3 Strain capacity at Failed and non-failed sites in armor steel sheet.

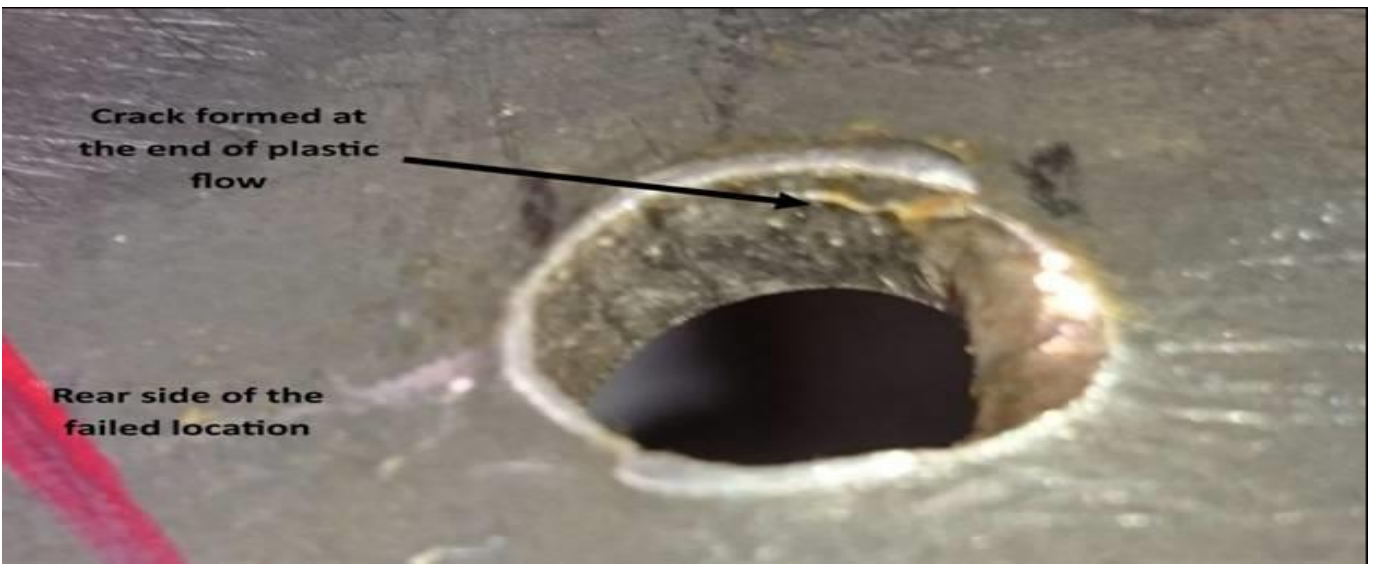

Fig. 4 Failed location at the rear side of $6 \mathrm{~mm}$ armor steel sheet.
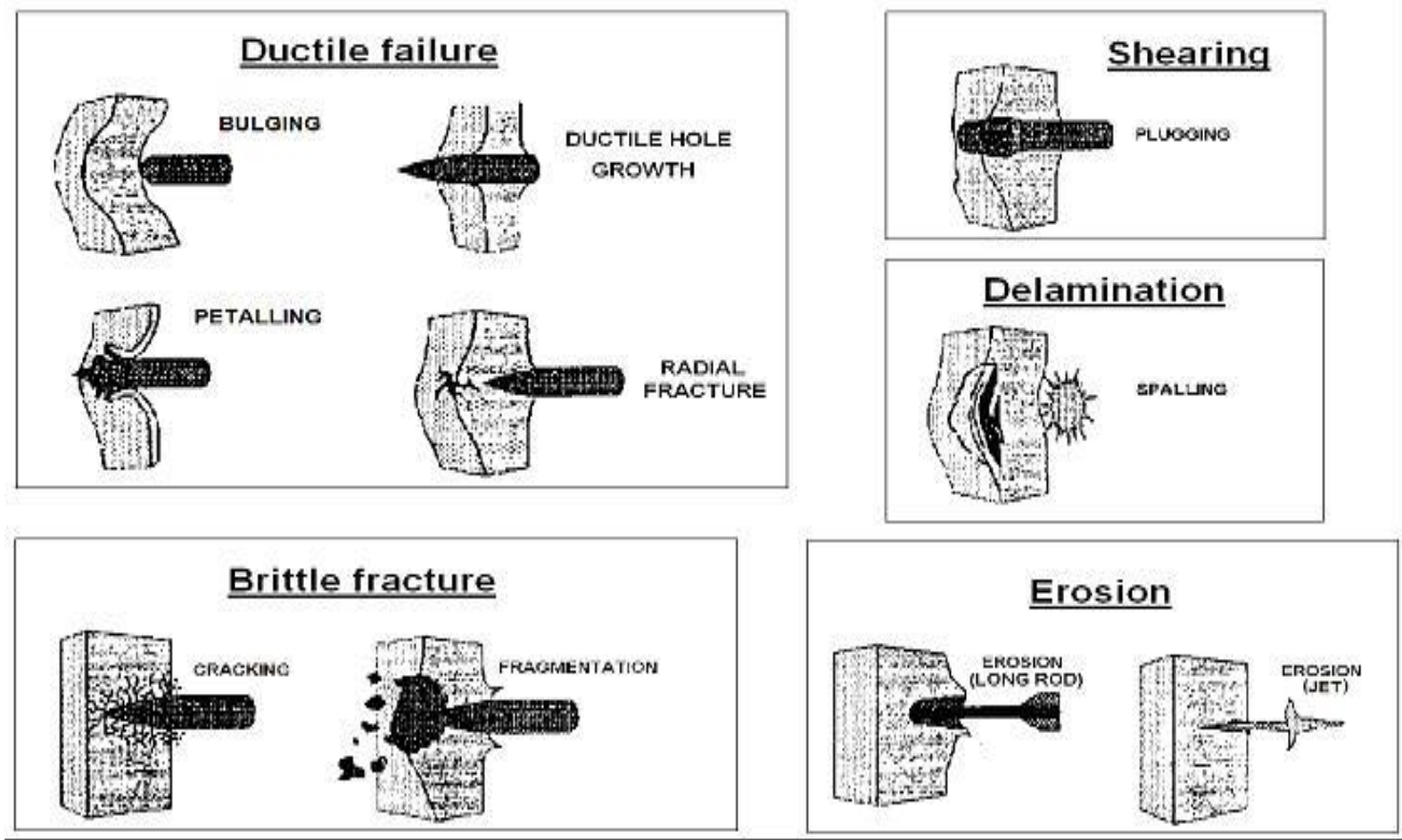

Fig. 5 Failed location at the rear side of $6 \mathrm{~mm}$ armor steel sheet [9]. 

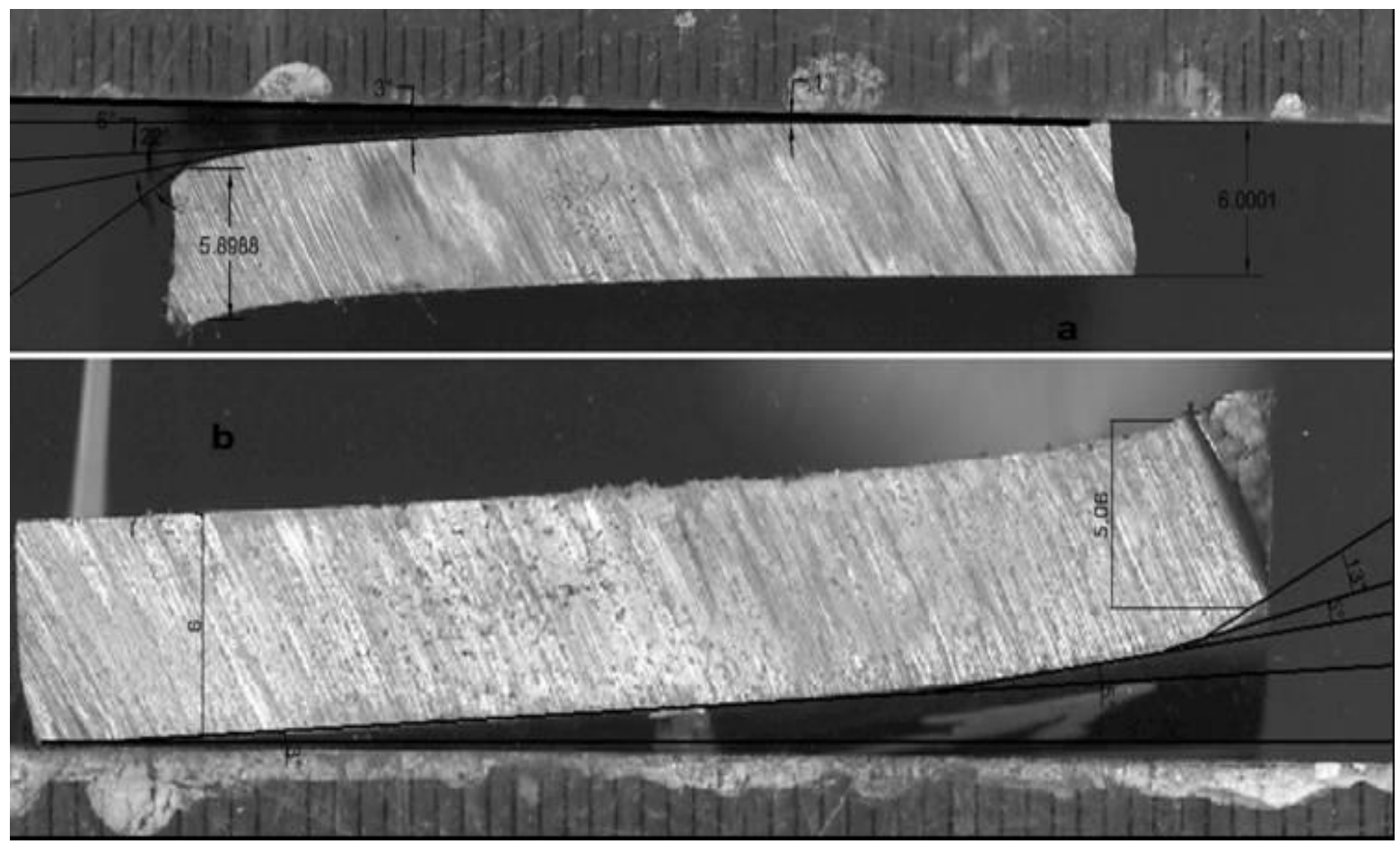

Fig. 6 Monitoring the deformation at the horizontal axis, a. failed area, b. non-failed area.

segregation of alloying elements. However, the increment of hardness at one side of sheet at the expense of the other side is a clear guide to the poor conditions of heat treatment. While, the segregation can be represented by peaks up and down in hardness among the steel sheet.

\subsection{Microstructure observations}

\section{5. a. Non- metallic inclusions}

Non-metallic inclusions are such micro-constituent that represent a stress concentration sites, and thereby they can act as a crack initiation site, promoting the premature failure of the matrix. Hence, they should be reduced to their lower rate. Non-metallic inclusions have been monitored and evaluated by using ASTME45 [10]. They have been monitored at different locations, including the ballistic tested locations, as given in Fig.10. It is observed that non-metallic inclusions are at their lower rate. In addition, they are following the low rate of thin inclusions according to ASTM E-45, as given in table 2.

\section{5.b. Microstructure observations}

Now, microstructure observations at either failed or non-failed sites are crucial. The main matrix of armor steel is tempered martensite, while it is expected to observe some retained austenite, and bainite according to the isothermal transformation in term of time, and temperature. Then, Microstructure was observed either closed to knock locations or far from them. As being expected regarding to low carbon content $<0.6 \%$, lath tempered martensite is the domain matrix at the three locations. However, the lath martensite of non-fail sites converted to very fine martensite close to knock locations, as given in Fig. 11, and 12. Surely, this interprets the twinning character of lath martensite against plastic deformation, and it is expected that this will reflect hardly on the hardness as will be discussed later in micro hardness observations. Figure 13 shows that tempered martensite at the failed site has never been transformed into fine structure, which is completely different from that has been observed at non-failed sites.

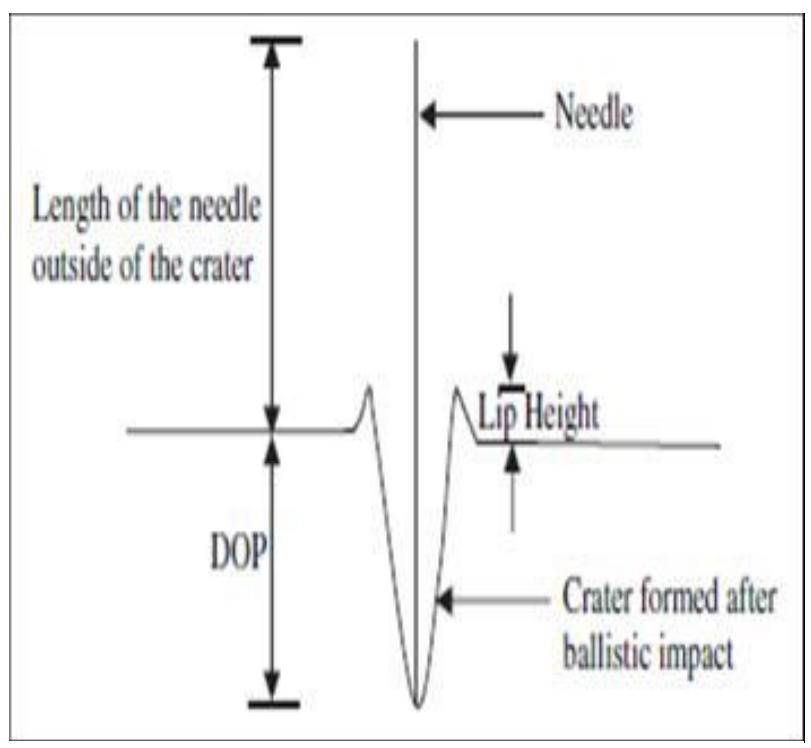

Fig. 7 Depth of penetration at non-failed sites [10]. 


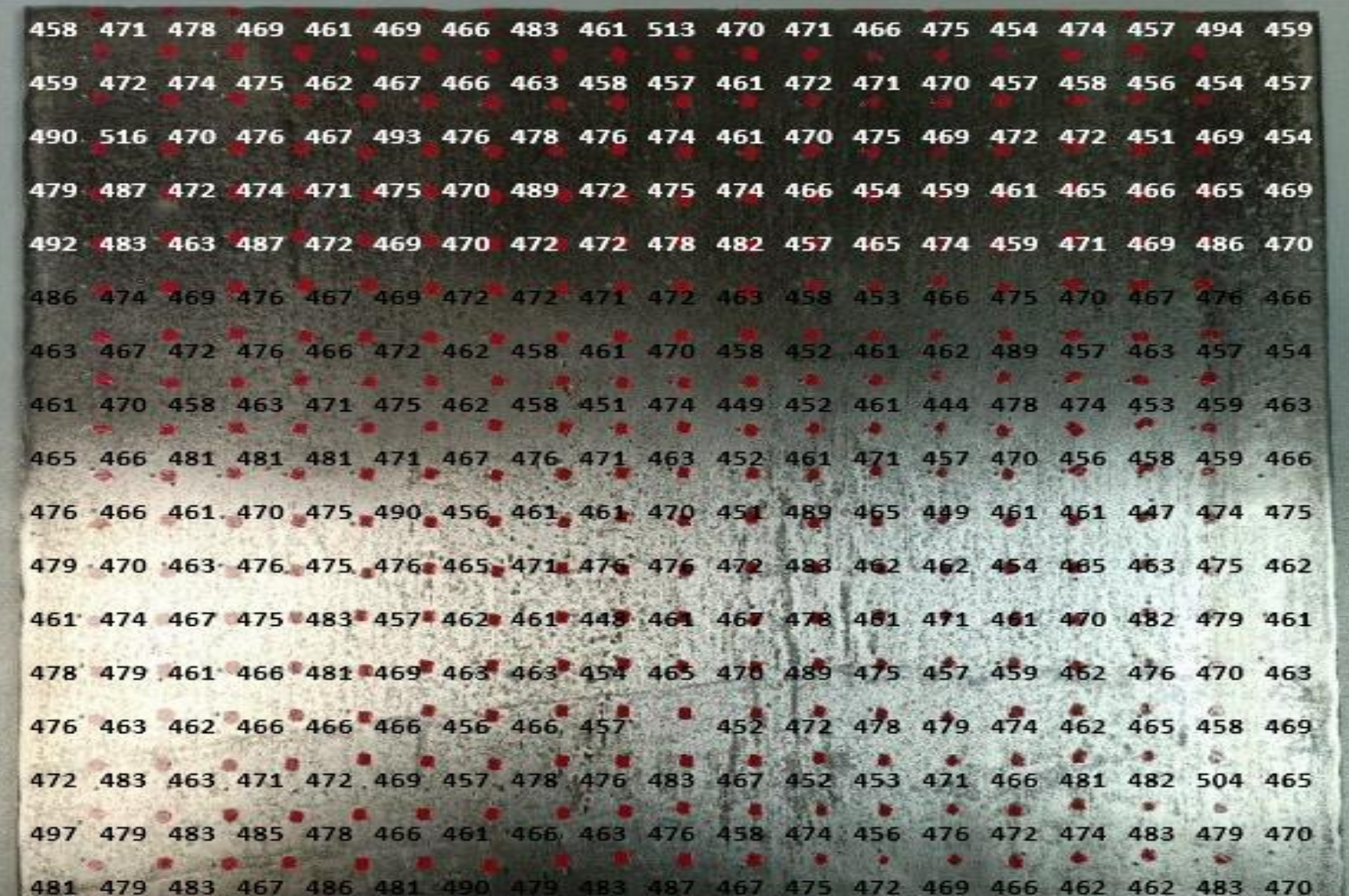

Fig. 8 The hardness map among the armor steel sheet.

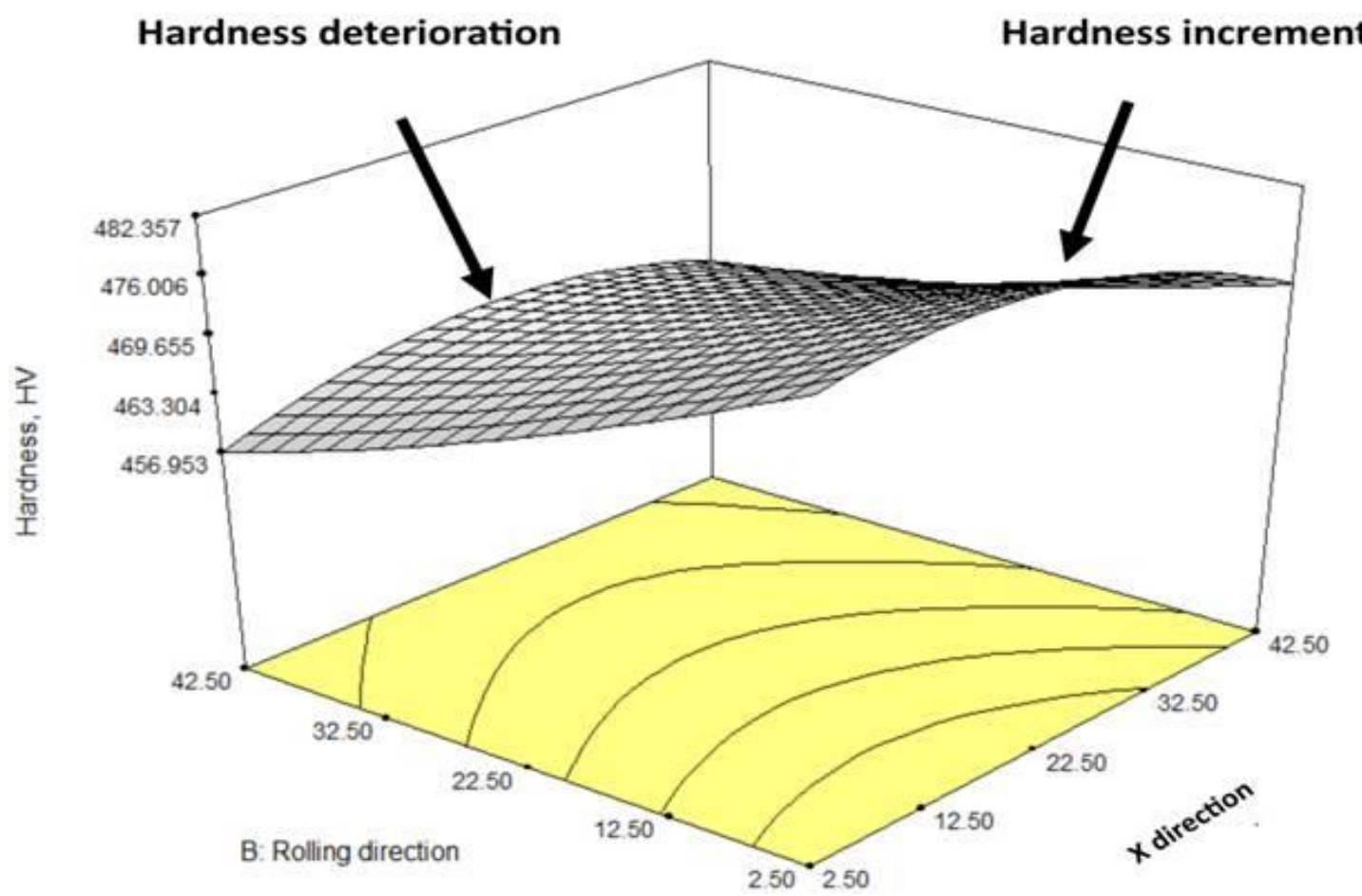

Fig. 9 The hardness contour among the armor steel sheet. 
Table 2. WORST FIELD INCLUSION RATINGS (METHOD A) according to ASTM E-45.

\begin{tabular}{|c|c|c|c|c|c|c|c|c|}
\hline \multirow{2}{*}{$\begin{array}{c}\text { SPECIMEN } \\
\text { NO. }\end{array}$} & \multicolumn{2}{|c|}{ TYPE A } & \multicolumn{2}{c|}{ TYPE B } & \multicolumn{2}{c|}{ TYPE C } & \multicolumn{2}{c|}{ TYPE D } \\
\cline { 2 - 9 } & THIN & THICK & THIN & THICK & THIN & THICK & THIN & THICK \\
\hline Non-fail location & 0.0 & 0.0 & 0.0 & 0.0 & 0.0 & 0.0 & 2.0 & 0.0 \\
\hline Non-fail location & 0.0 & 0.0 & 0.0 & 0.0 & 0.0 & 0.0 & 2.0 & 0.5 \\
\hline fail location & 0.0 & 0.0 & 0.0 & 0.0 & 0.0 & 0.0 & 1.5 & 0.0 \\
\hline fail location & 0.0 & 0.0 & 0.0 & 0.0 & 0.0 & 0.0 & 1.5 & 0.5 \\
\hline Non-fail location & 0.0 & 0.0 & 0.0 & 0.0 & 0.0 & 0.0 & 1.5 & 0.5 \\
\hline Non-fail location & 0.0 & 0.0 & 0.5 & 0.0 & 0.0 & 0.0 & 2.0 & 0.0 \\
\hline AVERAGE & 0.0 & 0.0 & 0.1 & 0.0 & 0.0 & 0.0 & 1.8 & 0.3 \\
\hline
\end{tabular}

Based on this microstructure, plastic deformation was less established at the failed location in comparison with that established at non-failed locations. Clearly, microstructure observations at the side of the hole at failed location refers to high fractions of polygonal ferrite. In addition, it is believed that the bright band should refer to either shear bands or poor carbon containing martensite as given in Fig.14. Certainly, micro hardness observations could be witness on which is the bright band.

\section{5.C. Microhardness observations}

Hardness of constituent phases was monitored by using micro-indenter. The hardness was recorded for different phases either close to knock area or far from knock area. In addition, the hardness was observed close, far, and inside the failed area, as given in Fig. 15, 16, 17, and 18. Fine tempered martensite with high hardness value was observed at the non-failed area either far or close to the knock area. However, the hardness closed to the knock location of failed area is much lower than the hardness observed at the nonfailed areas. In addition, there is a huge difference between the hardness of martensite far from the knock area and the hardness of martensite observed closed to the non-failed samples. However, no much difference in martensite hardness observed either at the failed samples closed or far from the knock area. Retained austenite is the most expected soft phase that can generate through the isothermal transformation in conjugation with martensite. Retained austenite has a significant effect on reducing the hardness of the treatment that have been applied on this armor steel sheet. As mentioned before, the hardness of bright band observed inside the hole should be a strong indication deformation multiplies the hardness of martensite. If it is shear band, then its hardness will be much higher than the tempered martensite, unless it is poor carbon containing martensite. Figure 17 shows that the bright area has a lower hardness value than that was observed at dark area, which should refer to the discrepancy of carbon content between the two areas.

martensite matrix, which is far from the knock area of non-failed area. Normally, retained austenite transformed into martensite, adding to the twinning of lath martensite regarding to the high strain rate plastic

Regarding to the aforementioned observations, it is clear that either the microstructure constituents or alloying elements segregation should be the powerful parameter in promoting the failure observed at the ballistic test. Then, using high magnification microscope, in conjugation with EDX software act step forward in interpreting the failure root cause at the ballistic test.

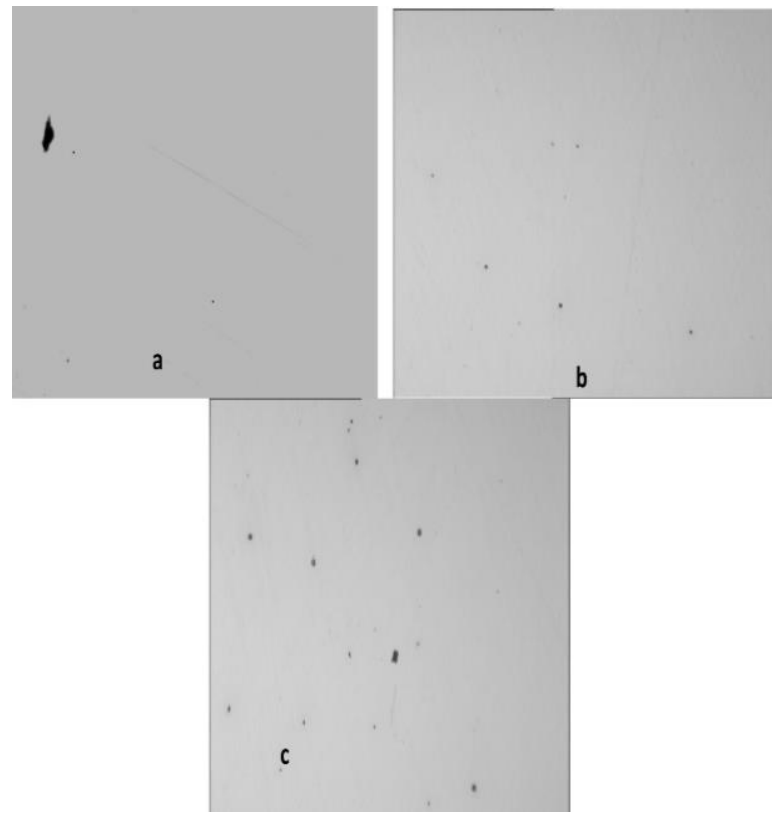

Fig. 10 NMI distribution at failed and non-failed sites of armor steel sheet.

It was mentioned before that the main structure of the armor steel investigated is tempered martensite, which should be observed clearly in either failed or non-failed structure. However, fine tempered martensite is observed in non-failed samples, with clear boundaries. While, there are blurred coarse martensite, and polygonal ferrite have been observed at the failed structure, as given in Fig. 19, and 20. In fact, blurred martensite is referring to bad condition of tempering either in term of time or temperature. In fact, the differentiation in the martensite morphology and size 

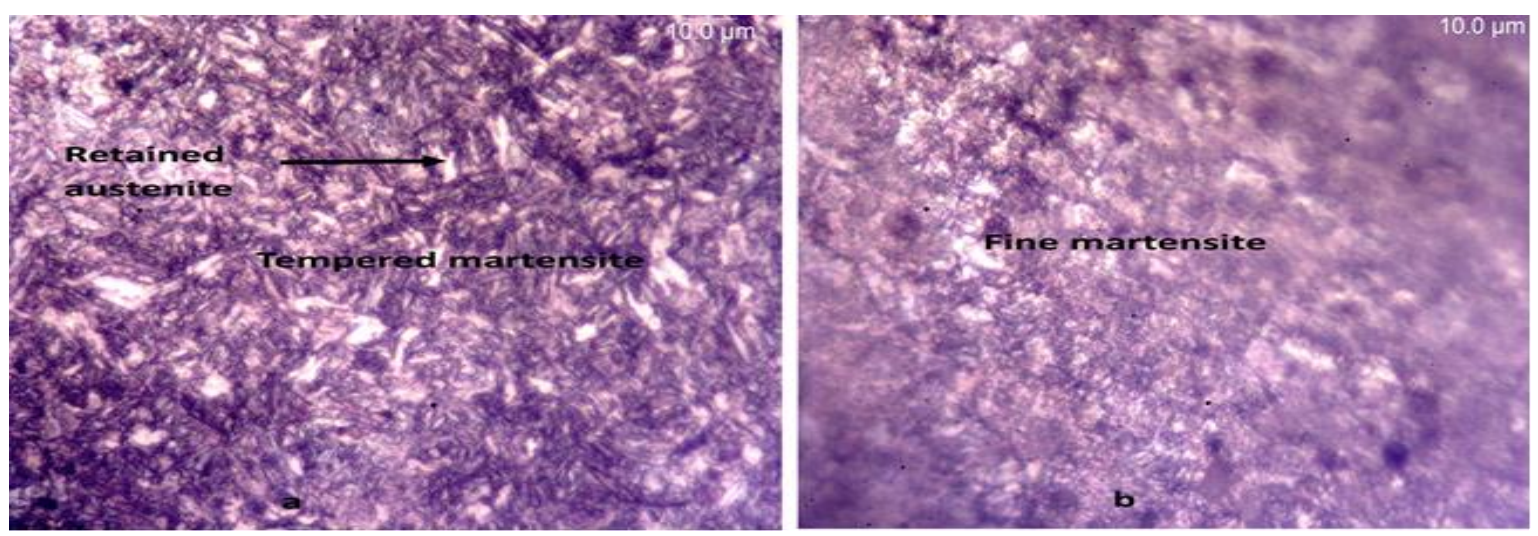

Fig. 11 Microstructure of non-failed site far and closed to knock location.
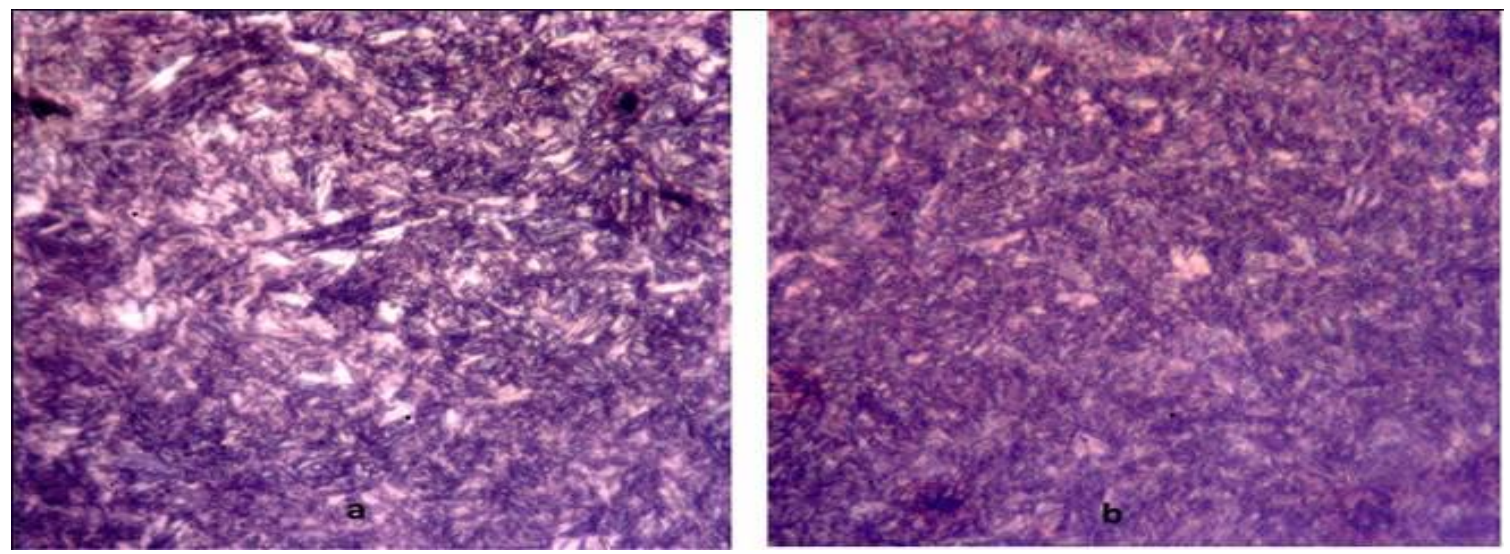

Fig. 12 Microstructure of non-failed site far and closed to knock location.

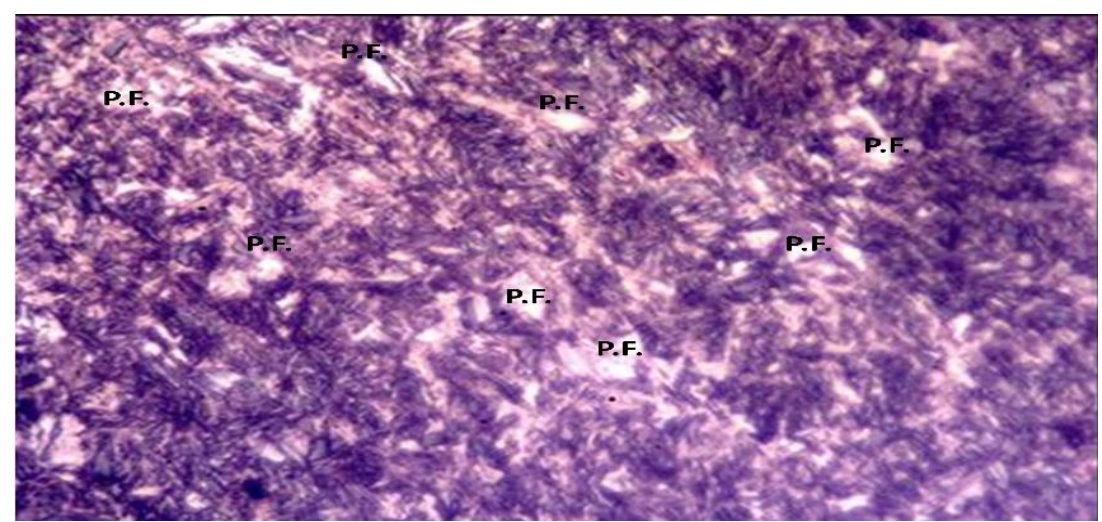

Fig. 13 Microstructure of failed site closed to knock location.

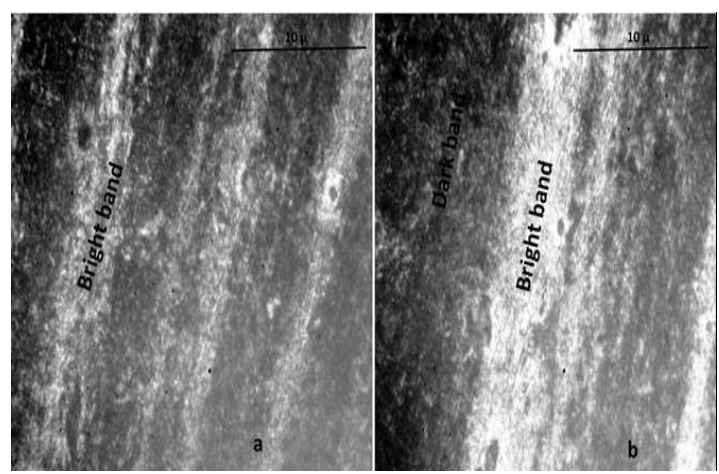

Fig. 14 The bright bands that have been observed inside the hole of failed site. 


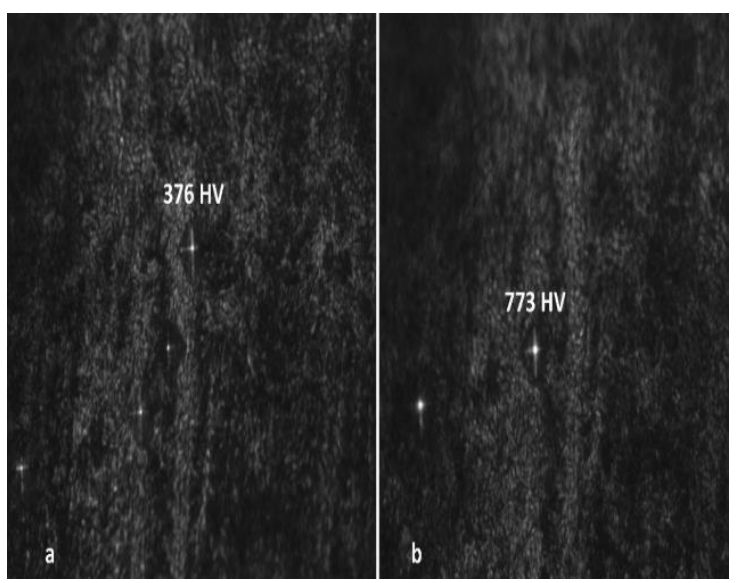

Fig.15 Microhardness of the martensite domain closed and far from the knock area of non-failed sample a. closed to knock area, b. far from knock area

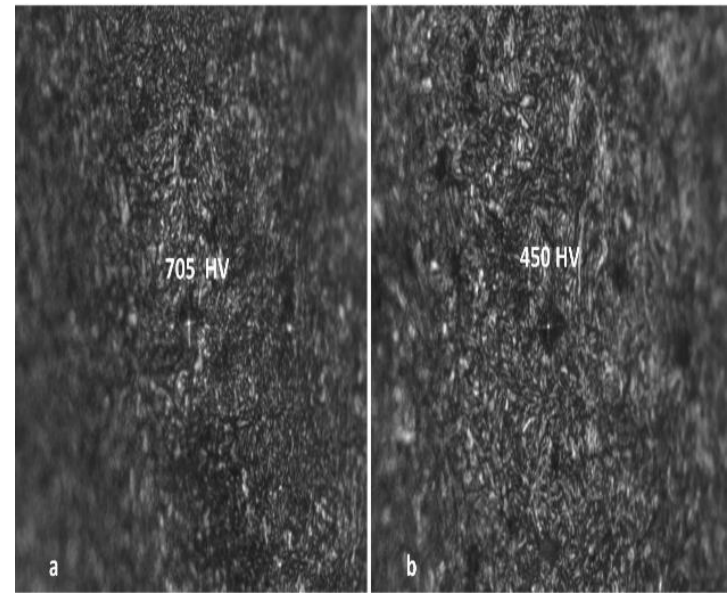

Fig. 16 Microhardness of the martensite domain closed and far from the knock area of non-failed sample a. closed to knock area, b. far from knock area

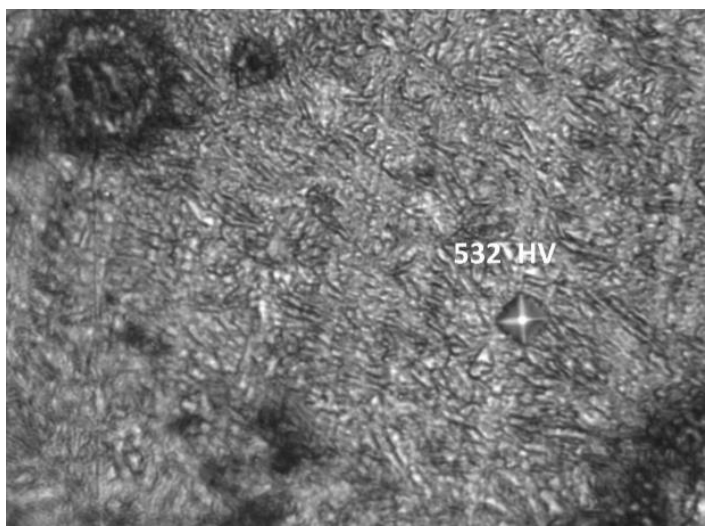

Fig. 17 Microhardness of the martensite domain closed from the knock area of failed sample https://doi.org/ 10.21608/ijmti.2021.181110
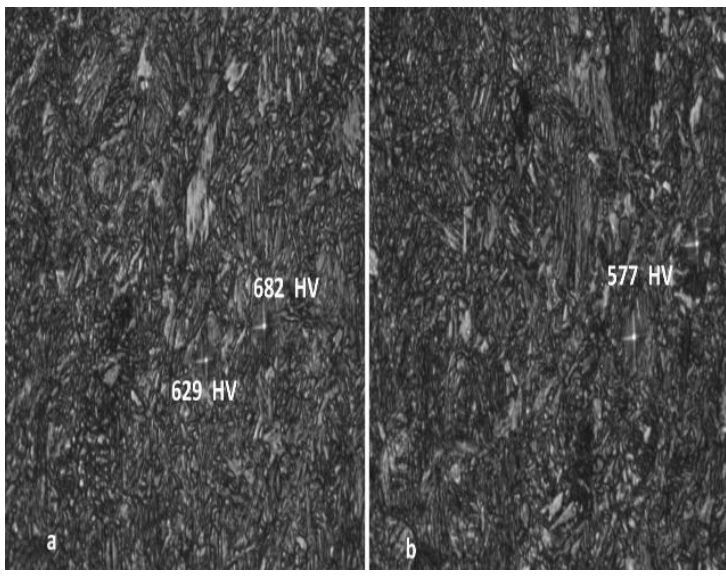

Fig. 18 Microhardness of the bright and dark band at the failed hole, a. bright band, b. dark band
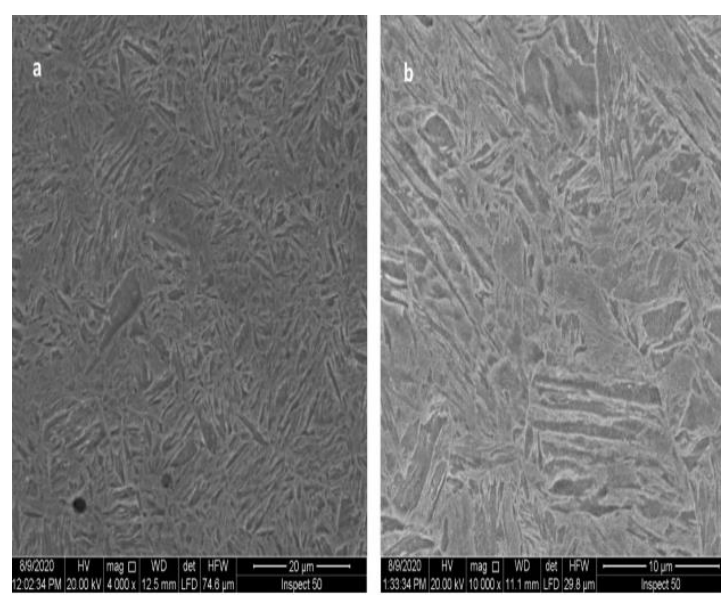

Fig. 19 SEM observations of non-failed structure

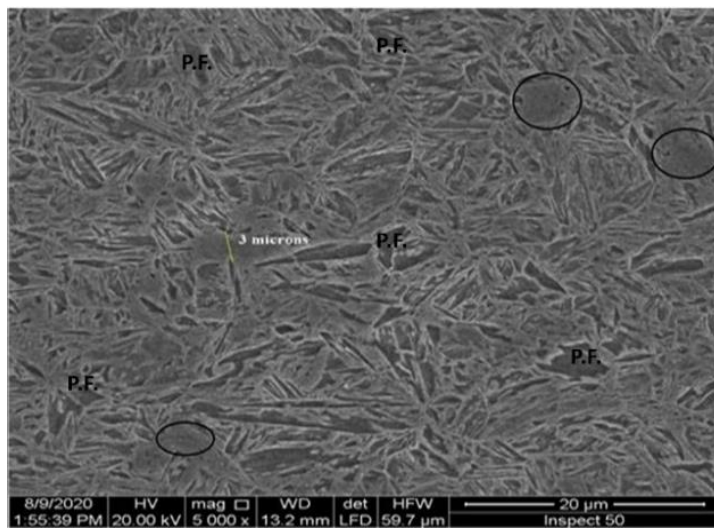

Fig. 20 SEM observations of failed structure 

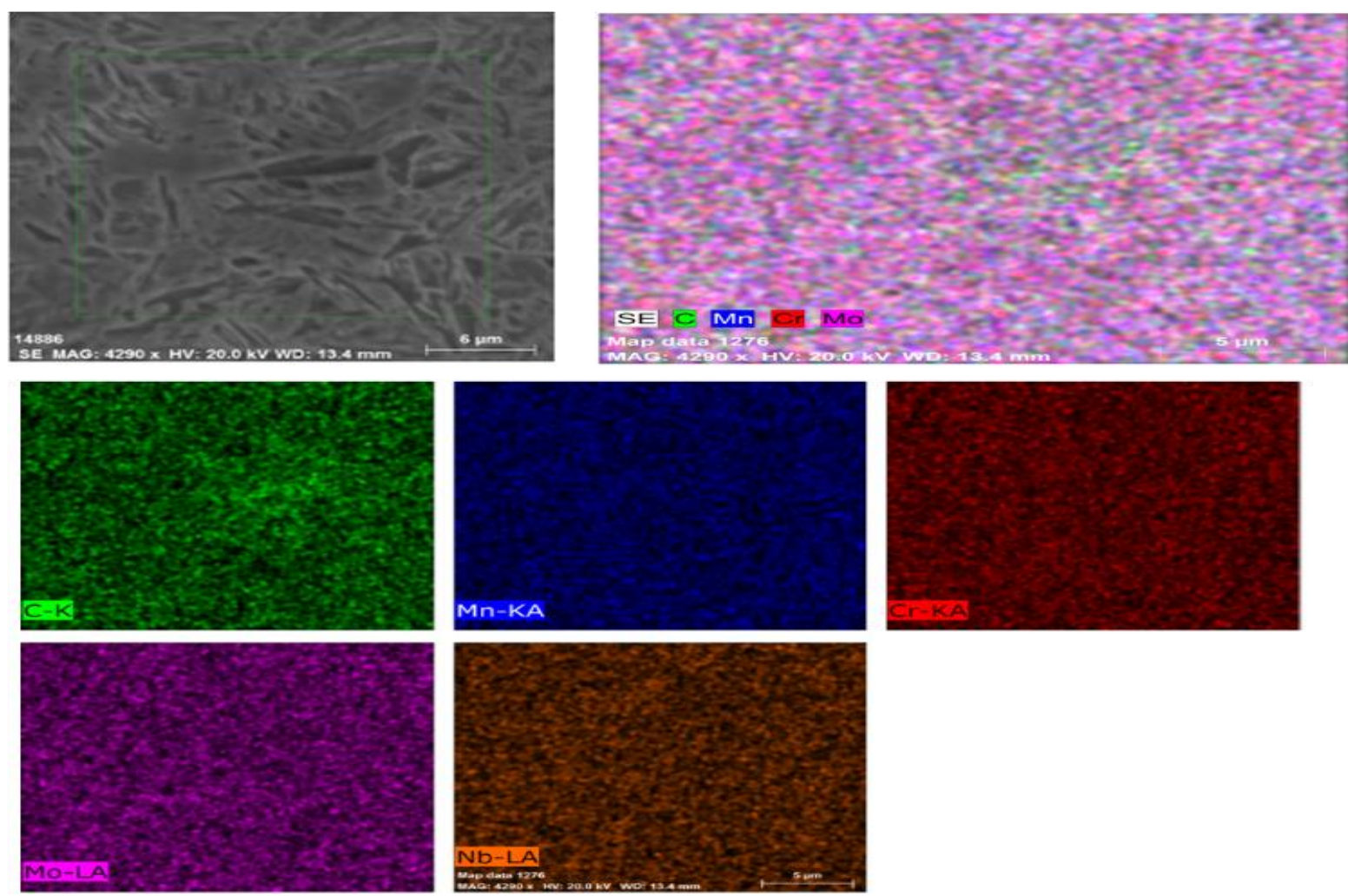

Fig. 21 EDX Mapping of alloying elements at the failed sample.

should be in relationship with its chemical compositions that will be observed by using EDX. Micro-segregation was tracked by using map technique for different alloying elements, including carbon, and it is clear that no segregation sign has been detected at the failed sample, as given in Fig. 21.

\section{D. XRD observations}

The constituent phases in term of crystallographic have been identified, using X-ray diffractometer Cobalt source. The variation in the constituent phases among the armor steel sheet was strongly detected. Figure 23 explains that the samples from the three knock sites have a different constituent phase. By comparing between the result of X-ray diffraction and the depth of penetration, it can be concluded that as long as $\mathrm{Fe}_{3} \mathrm{C}$ precipitates, the depth of penetration is increased. Moreover, it is believed now that $\mathrm{Fe}_{3} \mathrm{C}$ is the root cause of failure through the ballistic test. On contrary, as increasing retained austenite (FCC structure), the depth of penetration decreases, avoiding the failure at ballistic test. Then, it can be said that the unstable retained austenite is decomposed at some areas among the armor steel sheet into ferrite and cementite or bainite and cementite, and cementite promote the temper embrittlement. This observation is matched to what has been observed at SEM. In addition, FWHM of bcc at the main $2 \theta$ structure, and microstrain value have used to calculate the martensite crystallite size, using Scherrer's equation, and the dislocation density. It was found that the martensite crystallite size at failed site is much coarser than that was found at the other two nonfailed sites. It is well known that the density of dislocation among tempered martensite is inversely proportional to the tempering parameters (temperature, time). The mechanical meaning of reducing the density of dislocations is enhancing its mobility, which reflects on its low plastic strength as mentioned before. The density of dislocation has been calculated by using Eq. 2 [11].

$$
\rho=2 \sqrt{3 *}\left\langle e^{2}\right\rangle^{1 / 2} /(d * b)
$$

and dislocation density $\rho$ can be expressed in terms of the average crystallite size $d$, the Burgers vector $b$ and lattice strain e, where, $b=0.248 \mathrm{~nm}$, and $d$ has been calculated as in table 2 , e was determined from determining the change of lattice parameter based on the change of FWHM of the main peak of bcc structure. Then, Table 2 represents that the density of dislocation of failed sample is much less than that was determined at the other two non-failed samples.

As mentioned before, retained austenite was observed at one site of two non-failed sites by few fractions $5 \%$. It is well known that the stability of retained austenite is proportional to its carbon content. Based on XRD pattern, the carbon content is calculated as $1.2 \mathrm{wt} \%$, by 


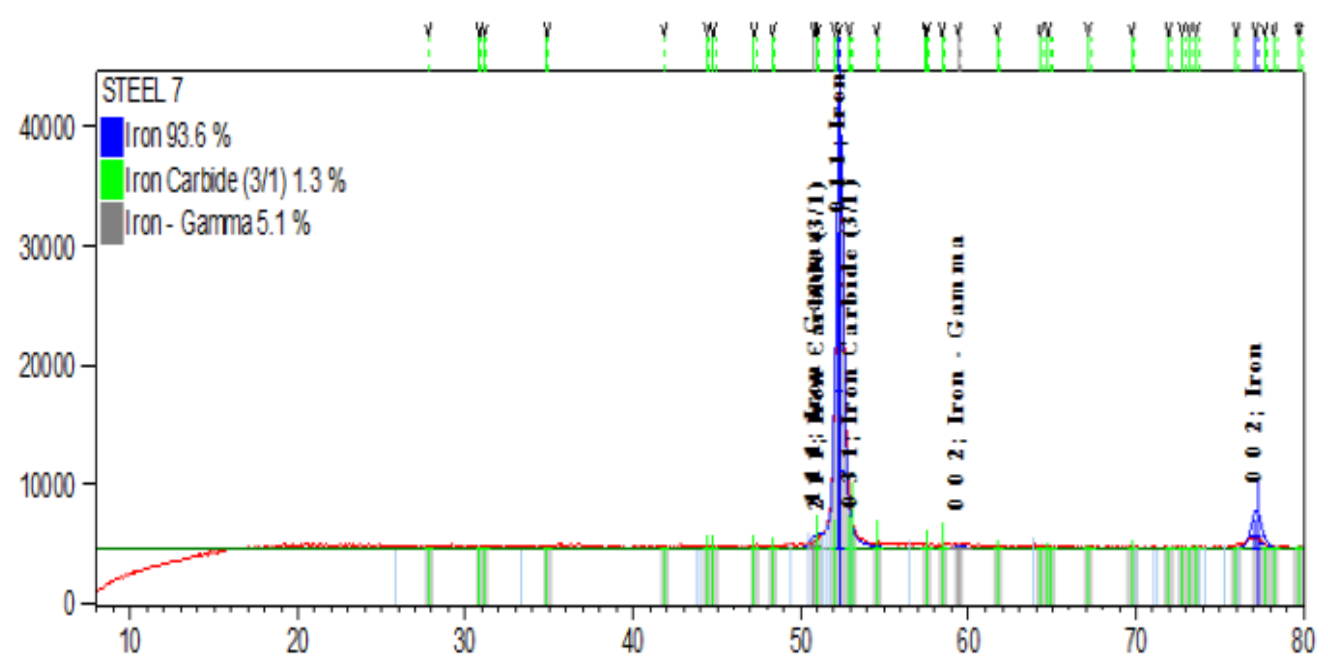

a. XRD pattern of non-failed sample
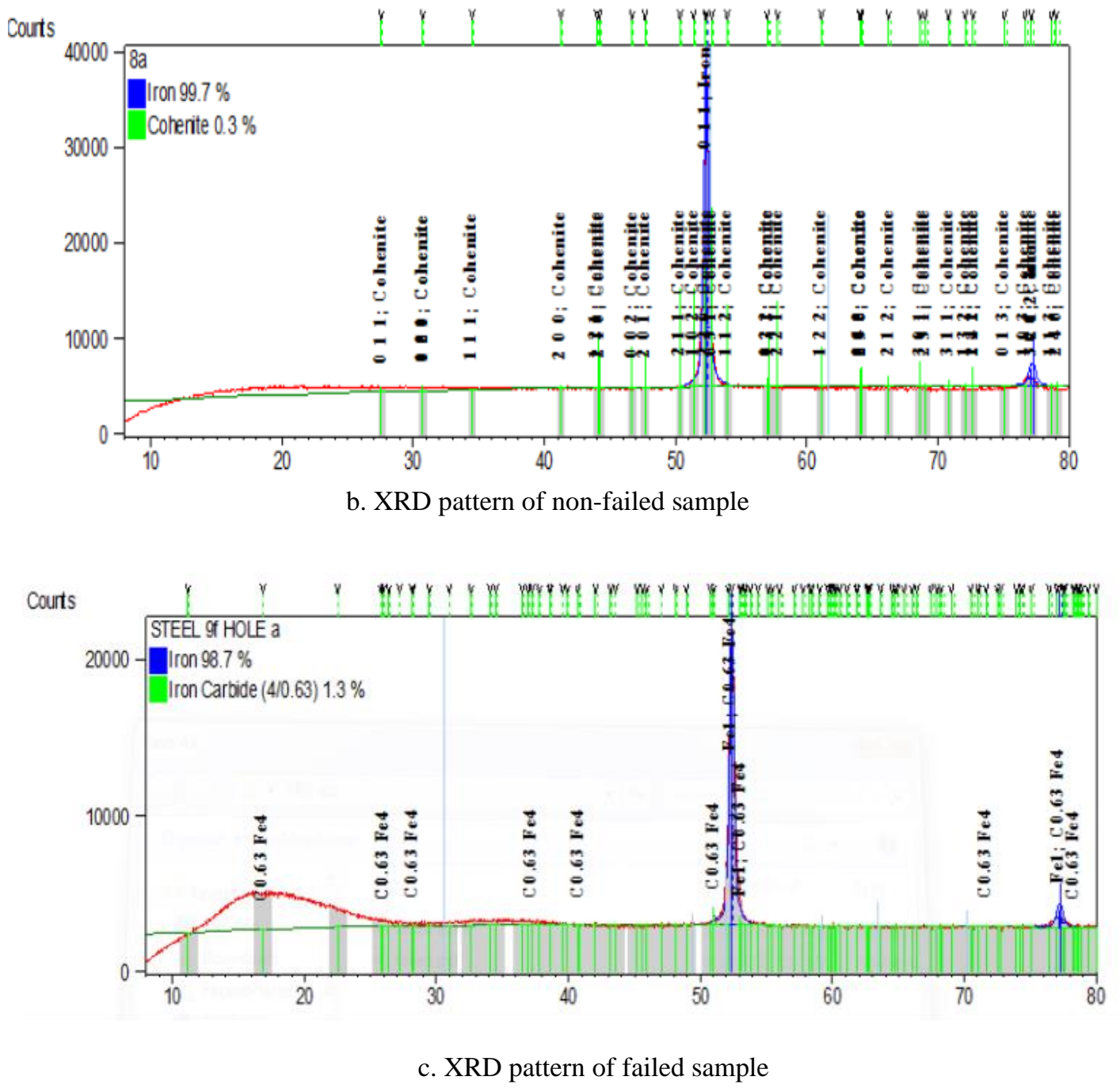

Fig. 22 XRD of three knock area at the ballistic test 
using Eq.3. In fact, this is considered as high carbon content, which can save much stability for austenite against induced plastic transformation, and it explains the low DOP of non-failed site [12].

$$
a_{0}=3.555+0.044 x
$$

Where, $\mathrm{a} 0$ is the lattice parameter of FCC structure (austenite), $\mathrm{x}$ is the carbon wt\%.

\subsection{Evaluation of heat treatment process at the industrial site}

As being observed, inhomogeneous microstructure should be considered as the root cause of the premature failure happened in armor sheet $6 \mathrm{~mm}$ thickness. Inhomogeneous microstructure should be attributed to the bad condition in heat treatment process. Thereby, the water quenching process at the industrial site has been monitored to evaluate the condition of the heat treatment process, as given in Fig. 23

It is believed that heat transfer conduction mechanism can be established at the austenizing armor sheet through emerging from the austenizing furnace, which can generate high fraction of polygonal ferrite instead of full martensite matrix. Certainly, high stress interface between the martensite and polygonal ferrite can promote the premature failure through the ballistic test of armor sheet.

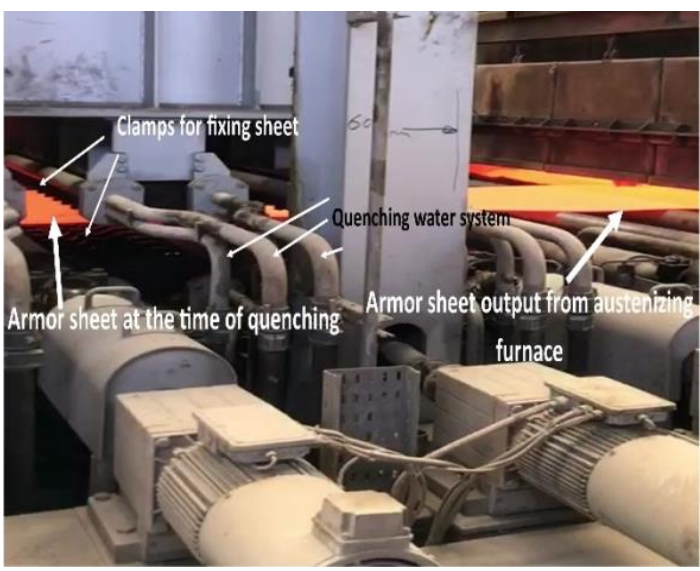

Fig. 23 The quenching mechanism of the armor steel sheet at the industrial site.

Certainly, the heat transfer mechanism should be confirmed by using simulation method based on FEA.

\subsection{Finite element simulation method of transient heat transfer mechanism}

By using of the geometry of the armor sheet, the dimensions of the austenizing furnace, the dimensions of withdrawal rolls, and the clamping system, FEA based on Solid work package has been used for simulating the transient heat transfer mechanism at the production site through 7 seconds (the actual time before clamping and quenching), as shown in Fig. 24,
Table 3. The change in $\mathrm{d}$, e $\%$, and dislocation density among different sites at armor steel sheet.

\begin{tabular}{|c|c|c|c|}
\hline Sample & $\begin{array}{c}\text { Average } \\
\text { crystalline } \\
\text { size, } \mathbf{d} / \mathbf{n m}\end{array}$ & $\begin{array}{c}\text { Lattice } \\
\text { strain, } \\
\mathbf{e} \%\end{array}$ & $\begin{array}{c}\text { Density } \\
\text { dislocation, } \\
\mathbf{1 0}^{-\mathbf{1 2}} \mathbf{~ m}^{-\mathbf{2}}\end{array}$ \\
\hline $\begin{array}{c}\text { Non-failed } \\
\text { site }\end{array}$ & 222.2 & 0.0960 & 0.0604 \\
\hline $\begin{array}{c}\text { Non-failed } \\
\text { site }\end{array}$ & 204.40 & 0.09424 & 0.06436 \\
\hline Failed site & 272.26 & 0.0517963 & 0.02657 \\
\hline
\end{tabular}

25 , and 26. It is observed that much reduction in the austenizing temperature at the armor sheet can be established, regarding to its low modulus profile (high ratio of surface area: volume). In addition, at fractions of seconds the temperature of the studied sheet has been reduced rather than the austenizing temperature $830 \mathrm{oC}$ by more than $100^{\circ} \mathrm{C}$, which will affect directly on the percentage of ferrite and martensite. In addition, it can be observed the high fluctuation of temperature at the same time among the surface of the armor sheet.

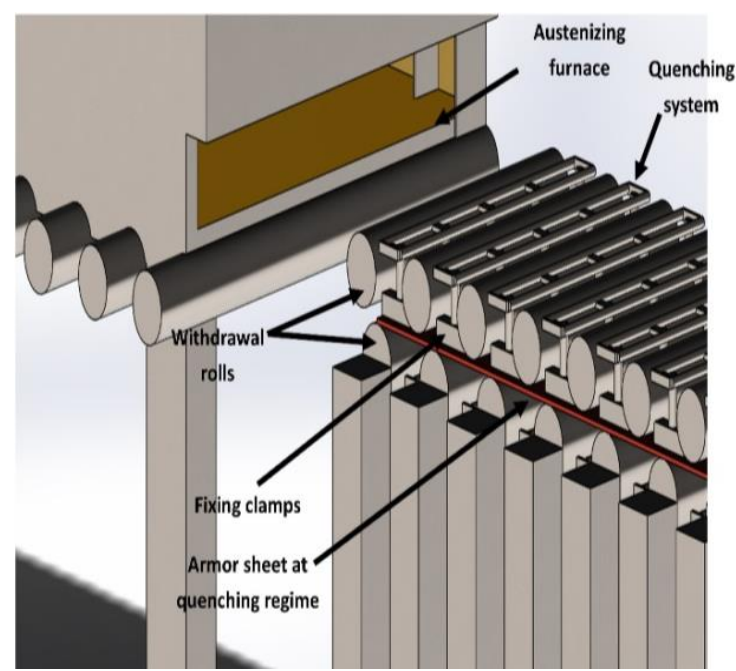

Fig. 24 Illustration diagram of the quenching regime of the armor steel sheet at the industrial site.

\section{Conclusions}

1. poor heat treatment conditions should have a significant role on deteriorating the ballistic property among the armor steel sheet $6 \mathrm{~mm}$.

2. Quenching temperature must have been controlled to be appropriate for the low modulus geometry as sheet. In addition, optical, SEM show that inhomogeneity in structure was established among failed and non-failed sites of the armor sheet investigated. Precipitations accompanied 


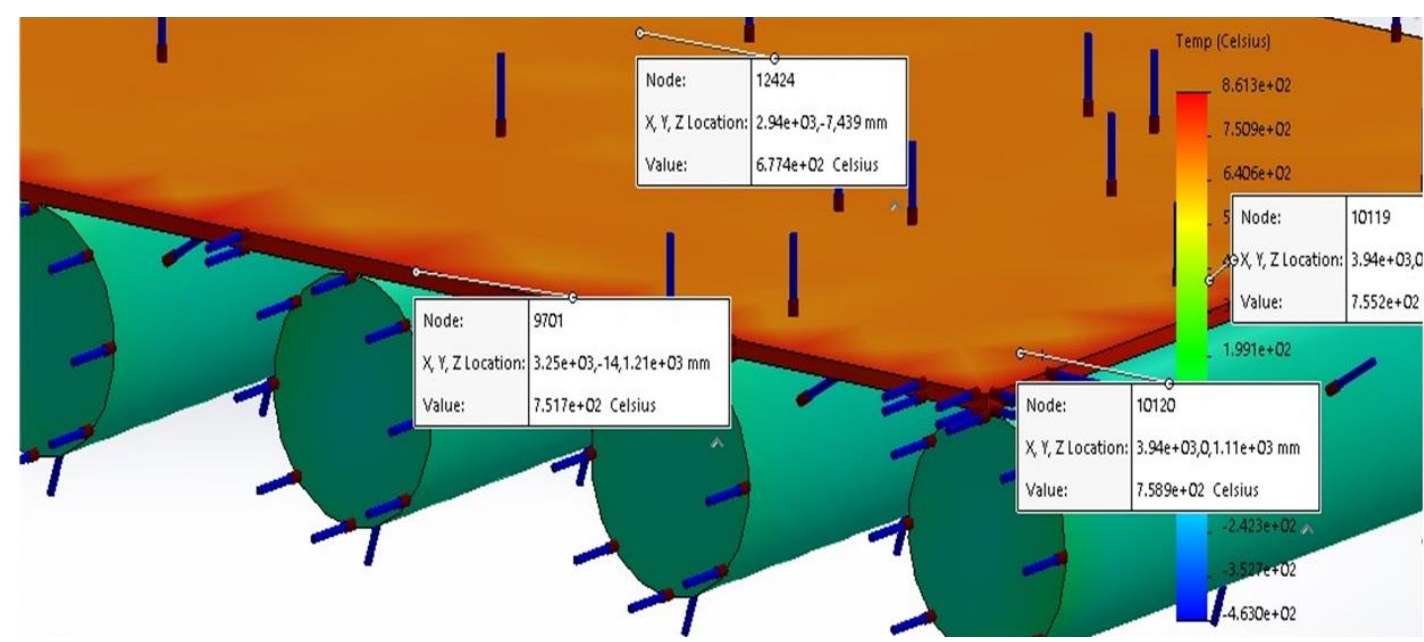

Fig. 25 FEA of the transient heat transfer among the armor sheet through 7 seconds before quenching regime.

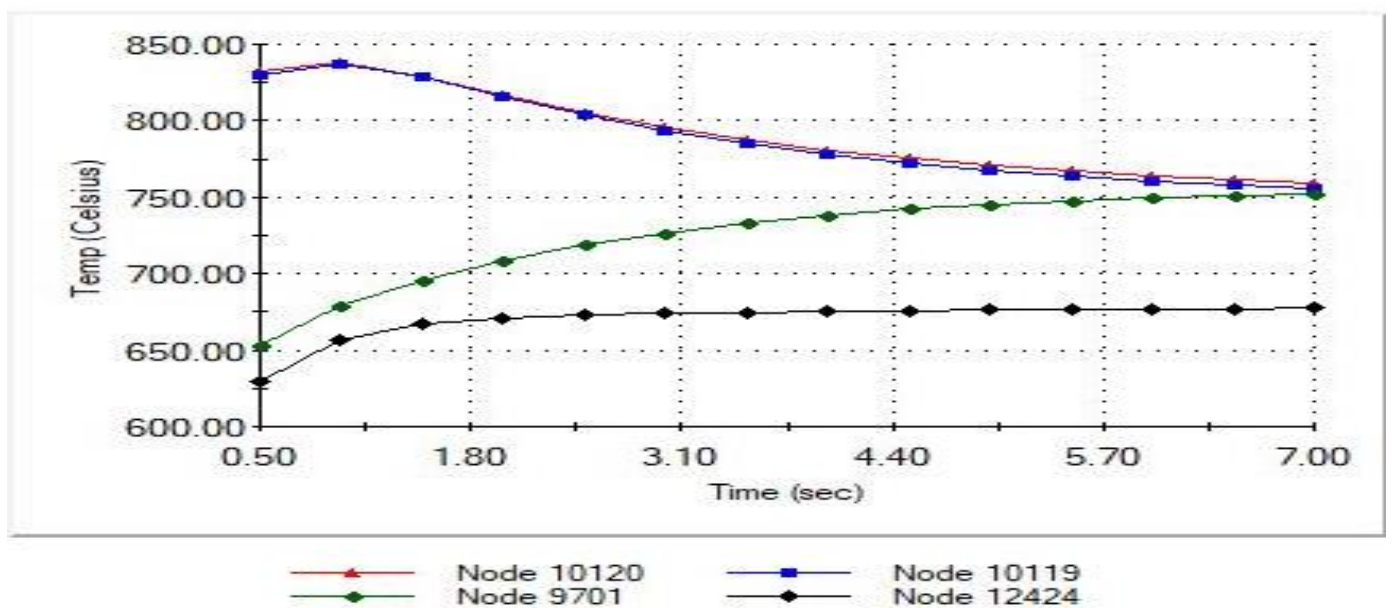

Fig. 26 Transient heat transfer diagram at different locations among the austenizing armor sheet.

with coarse martensite structure have been detected at the failed site, which should refer to the bad condition in tempering regime.

3. The discrepancy of hardness among the steel sheet by using hardness map confirmed the bad conditions of quenching regime.

4. XRD proved that insufficient retained austenite, with coarse martensite have been detected at the site failed, while sufficient percentage of Retained austenite with fine martensite structure have been detected at non-failed site.

\section{References}

[1] B. Mishra, B. Ramakrishna, P. K. Jena, K. Siva Kumar, V. Madhu, N. K. Gupta, Experimental studies on the effect of size and shape of holes on damage and microstructure of high hardness armor steel plates under ballistic impact, Materials \& Design 43 (2013) 17-24.

[2] A. G. Odeshi, M. N. Bassim, M. Bolduc., Damage mechanism in high hardness armor (HHA) steel subjected to V50 ballistic impact, DYMATInternational Conference on the Mechanical and Physical Behaviour of Materials under Dynamic Loading. Vol. 1. EDP Sciences, (2009) 563-567.

[3] P. P. Senthil, B. B. Singh, K. S. Kumar, A. K. Gogia, Effect of heat treatment on ballistic performance of an armour steel against long rod projectile, International Journal of Impact Engineering 80 (2015) 13-23.

[4] P. K. Jena, Ponguru Senthil P., Siva Kumar K., Effect of tempering time on the ballistic performance of a high strength armour steel, 
Journal of applied research and technology, 14,1 (2016) 47-53.

[5] K. Maweja, W. Stumpf, The design of advanced performance high strength low-carbon martensitic armour steels: Part 1. Mechanical property considerations, Materials Science and Engineering: A, 485, 1-2 (2008) 140-153.

[6] P. k. Jena, B. Mishra, M. Rameshbabu, A. Babu, A. K. Singh, K. Sivakumar, T. B. Bhat, Effect of heat treatment on mechanical and ballistic properties of a high strength armour steel, International Journal of Impact Engineering, 37,3, (2010) 242-9.

[7] G. Shigesato, T. Fujishiro, T. Hara, Grain boundary segregation behavior of boron in low-alloy steel, Metallurgical and Materials Transactions A, 45,4, (2014) 1876-82.

[8] J. Venezuela, Q. Liu, M. Zhang, Q. Zhou, A. Atrens, A review of hydrogen embrittlement of martensitic advanced high-strength steels, Corrosion Reviews, 34,3, (2016) 153-186.

[9] A. Popławski, P. Kędzierski, A. Morka, Identification of Armox 500T steel failure properties in the modeling of perforation problems, Materials \& Design, 190, (2020) 108536.

[10] J. Feng, W. Sun, Z. Liu, C. Cui, X. Wang, An armour-piercing projectile penetration in a doublelayered target of ultra-high-performance fiber reinforced concrete and armour steel: Experimental and numerical analyses, Materials \& Design, 102, (2016), 131-141.

[11] C. Moreno-Castilla, M. A. Alvarez-Merino, F. Carrasco-Marín, J. L. G. Fierro, Tungsten and tungsten carbide supported on activated carbon: surface structures and performance for ethylene hydrogenation, Langmuir, 17,5,(2001), 1752-1756.

[12] J. Holmberg, A. Steuwer, A. Stormvinter, H. Kristoffersen, M. Haakanen, J. Berglund, Residual stress state in an induction hardened steel bar determined by synchrotron-and neutron diffraction compared to results from lab-XRD, Materials Science and Engineering: A, 667(2016),199-207. 